\title{
Erratum to: An Experimental Study of Algorithms for Controlling Palletizers
}

Frank Gurski, Jochen Rethmann and Egon Wanke

\section{Erratum to:}

Chapter "An Experimental Study of Algorithms

for Controlling Palletizers" in: K.F. Doerner et al. (eds.), Operations Research Proceedings 2015, Operations Research Proceedings, DOI 10.1007/978-3-319-42902-1_4

The original version of the book was inadvertently published with an inline figure in the chapter "An Experimental Study of Algorithms for Controlling Palletizers", which had to be deleted. The erratum chapter has been updated accordingly.

The updated online version of this chapter can be found athttp://dx.doi.org/10.1007/978-3-31942902-1_4 